\title{
Predictors of Functional Capacity in Patients with Pulmonary Hypertension
}

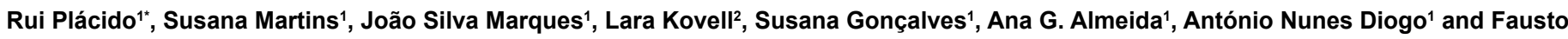
Pinto ${ }^{1}$

${ }^{1}$ Hospital Santa Maria, Serviço de Cardiologia I, Lisbon Academic Medical Centre, CCUL, Lisbon, Portugal

${ }^{2}$ Division of Cardiology, Department of Medicine, Johns Hopkins University School of Medicine, Baltimore, Maryland, USA

\section{Abstract}

Introduction: The 6-minute walk test (6 MWT) distance is frequently used in the prediction of pulmonary hypertension $(\mathrm{PH})$ prognosis. However, potential surrogates of this measure have not been established. We aim to describe the clinical, echocardiographic, and laboratorial criteria determining the 6 MWT distance in patients with PH.

Methods: In 22 consecutive PH patients, functional capacity was evaluated by the 6 MWT distance and compared with levels of neurohormonal activation biomarkers and echocardiographic parameters for right ventricular (RV) function.

Results: A correlation between the 6 MWT distance and several clinical parameters was found: Borg's pre-test classification $(R=-0.46 ; p=0.038) ;$ WHO functional class $(p=0.029)$. Patients with higher levels of aldosterone $(R=-0.46$; $p=0.030)$, renin $(R=-0.43 ; p=0.046)$ and mid-regional pro-adrenomedullin (MR-proADM, $R=-0.53 ; p=0.009)$ had worse 6 MWT performance. The opposite was true for natremia levels $(R=0.55 ; p=0.006)$. There was a positive correlation between the 6 MWT distance and RV global longitudinal peak systolic strain rate and early diastolic strain rate $(R=0.49$; $p=0.038$ and $R=-0.55 ; p=0.018$, respectively). On multivariate analysis, only natremia and early diastolic strain rate were predictors of the 6 MWT distance.

Conclusion: The 6 MWT distance correlated with renin-angiotensin-aldosterone system activation and parameters for RV myocardial deformation. The new biomarker MR-proADM proved to be useful in the prediction of the functional capacity.

Keywords: Pulmonary hypertension; 6-Minute walk test; Biomarkers; Echocardiography; Prognosis

\section{Introduction}

Pulmonary hypertension $(\mathrm{PH})$ is defined as an increase in mean pulmonary arterial pressure $\geq 25 \mathrm{mmHg}$ at rest as assessed by right heart catheterization [1]. The prognosis of patients with PAH has improved with modern therapies, but patient outcomes overall remain poor [2,3]. Identification of prognostic markers (clinical, laboratorial and genetic) to early find high risk subgroups is crucial.

In the recent years, in addition to a better understanding of the pathophysiological mechanisms underlying $\mathrm{PH}$, there has been significant development of methods and interventions with diagnostic and prognostic relevance addressing this disease, with a particular interest in biomarkers. Since there is no single variable that provides sufficient diagnostic and prognostic information, a comprehensive assessment and multidimensional approach is required. In patients with $\mathrm{PH}$, the 6-min walk test (6 MWT) distance provides an assessment of exercise capacity. Because limited functional capacity profoundly influences the clinical status, changes in 6 MWT distance have been employed as an endpoint in clinical studies conducted for regulatory approval in patients with $\mathrm{PH}$ of different etiologies [4,5]. A 15\% decrease in the 6 MWT distance coupled with other clinical markers suggesting deterioration or escalation of medical therapy has been included in definitions of "time to clinical worsening" end points [1].

Anthropometric factors, physical activity, chronic illness and motivation are known to influence the 6 MWT distance [1]. However, the predictive value of some parameters that have been utilized as endpoints in overall functional capacity, reflecting $\mathrm{PH}$ severity, is not well established. Therefore, we aim to establish clinical, echocardiographic and laboratorial parameters associated with 6 MWT distance and relevant to further prognostic assessment, and to better define mechanisms underlying functional changes together with their value as markers of disease modification in $\mathrm{PH}$.

\section{Methods}

\section{Study design}

We carried out a prospective cohort study of 22 consecutive $\mathrm{PH}$ patients followed in $\mathrm{PH}$ clinic. Inclusion criteria comprised the presence of symptomatic (WHO functional class II-IV) PH types I and IV (clinical classification [1]). PH was defined as mean pulmonary artery pressure $\geq 25 \mathrm{mmHg}$, assessed by right heart catheterization. Patients were excluded if they had a history of surgery or major trauma in the two months prior to inclusion, active neoplastic disease, liver cirrhosis or myocardial infarction. All patients were treated according to the European Society of Cardiology/European Respiratory Society (ESC/ERS) recommendations [4]. The study was approved by local ethics committee.

Patients underwent clinical assessment with WHO functional class and Borg Scale for Perceived Dyspnea along with echocardiographic evaluation and exercise capacity assessment through 6 MWT.

\section{Biochemical analyses}

Several biomarkers were determined: uric acid, amino-terminal pro-brain natriuretic peptide (NT-proBNP), troponin I, mid-regional pro-adrenomedullin (MR-proADM) and aldosterone.

*Corresponding author: Rui Plácido, Hospital Santa Maria (Centro Hospitalar Lisboa Norte) Serviço de Cardiologia I, Avenida Professor Egas Moniz 1649-035, Lisboa, Portugal, E-mail: placidorui@gmail.com

Received November 28, 2014; Accepted October 26, 2015; Published October 30, 2015

Citation: Plácido R, Martins S, Marques JS, Kovell L, Gonçalves S, et al., (2015) Predictors of Functional Capacity in Patients with Pulmonary Hypertension. J Pulm Respir Med 5: 290. doi:10.4172/2161-105X.1000290

Copyright: @ 2015 Plácido R, et al. This is an open-access article distributed under the terms of the Creative Commons Attribution License, which permits unrestricted use, distribution, and reproduction in any medium, provided the original author and source are credited. 
EDTA-plasma samples were collected from an antecubital vein after 5 minutes of rest. Complete blood and platelet counts, serum creatinine, sodium, urea, uric acid, troponin I, NT-proBNP, aldosterone and renin were processed and analyzed in the hospital laboratory. NTproBNP levels were determined on solid phase immunometric assay Immulite 2000 (Siemens Healthcare Global ${ }^{\circ}$, Breda, The Netherlands), commercially available and validated in the clinic. Blood osmolality was calculated using the following formula: osmolality $=1.86 \times$ [sodium $(\mathrm{mmol} / \mathrm{L})]+[$ glucose $(\mathrm{mg} / \mathrm{dL})] / 18+[$ Urea $(\mathrm{mg} / \mathrm{dL})] / 5992+9$. Aliquots of plasma samples were stored at $-80^{\circ} \mathrm{C}$ for further analysis.

\section{Echocardiography}

A GE Vivid 7 Dimension echocardiography machine was used. Digital images were post-processed in EchoPAC Dimension software (GE Healthcare ${ }^{\oplus}$, Milwaukee, WI). All patients underwent a complete transthoracic echocardiogram, performed according to the recommendations of the American Society of Echocardiography [6-8]. Standard two-dimensional echocardiographic evaluation of left ventricular (LV) and right ventricular (RV) size and function was performed. The following indices were obtained from the apical 4-chamber view: RV basal end-diastolic dimension; RV fractional area change [(RV end-diastolic area - RV end-systolic area)/RV enddiastolic area]; and maximal tricuspid annular plane systolic excursion (TAPSE). RV wall thickness was measured from the subcostal view. The peak tricuspid regurgitation velocity, recorded by continuous wave Doppler echocardiography, was selected from multiple standard views and the values from 3 consecutive beats were averaged. The pulmonary artery systolic pressure was calculated as the sum of the peak systolic tricuspid pressure gradient (calculated by modified Bernoulli equation from peak tricuspid regurgitation velocity) and estimated right atrial pressure (according to inferior vena cava size and respiratory kinetics).

Colour-coded tissue Doppler images of the RV free wall were obtained from the apical 4-chamber view ensuring a frame rate of $>100$ frames/s. Speckle-tracking analysis was used to generate regional myocardial strain and displacement. RV longitudinal strain was assessed in apical four-chamber views. Myocardial deformation was expressed as the percentage change from the original dimension at end-diastole. Myocardial lengthening was represented as a positive value and myocardial shortening was represented as a negative value. Values obtained in the basal and mid-ventricular segments were averaged together to obtain the following measurements: RV peak global longitudinal systolic strain; RV peak global longitudinal systolic strain rate (GLSRs); RV peak global longitudinal early diastolic strain rate (GLSRe); RV peak global longitudinal end-diastolic strain rate (GLSRa).

\section{Statistical analysis}

Continuous variables were presented as median and inter-quartile range. Categorical variables were presented as a number and percentage. The differences between these variables were calculated using the chisquare test. The multivariate model was based on an algorithm using all biomarkers tested.

Correlations between MR-proADM and other variables were explored using Pearson's test. A p-value $\leq 0.05$ was considered significant in all tests. The statistical software IBM SPSS Statistics ${ }^{\bullet}$ version 20.0 (IBM GmbH, Ehningen, Germany) was used.

\section{Results}

Detailed clinical, laboratorial and echocardiographic characteristics of the 22 patients are described in Table 1 . The median age was 60.0

\begin{tabular}{|c|c|}
\hline Variables' & Global (n=22) \\
\hline \multicolumn{2}{|l|}{ Clinic and Demographic } \\
\hline Age (years), median (IQR) & $60.0(43.0-67.5)$ \\
\hline Female gender, No. (\%) & $15(68)$ \\
\hline \multicolumn{2}{|l|}{ Etiologic classification (Dana Point) } \\
\hline -Group I, No. (\%) & $17(77)$ \\
\hline -Group IV, No. (\%) & $5(23)$ \\
\hline Mean PAP (cath, mmHg), median (IQR) & $46.5(36.8-55.0)$ \\
\hline Vasoreactivity, No. (\%) & $3.0(11.0)$ \\
\hline \multicolumn{2}{|l|}{ WHO class } \\
\hline -Class II, No (\%) & $16(73)$ \\
\hline -Class III, No. (\%) & $4(18)$ \\
\hline -Class IV, No. (\%) & $2(9)$ \\
\hline 6MWT distance, median (IQR) & $352.5(253.0-419.0)$ \\
\hline \multicolumn{2}{|l|}{ Baseline treatment, No. (\%) } \\
\hline -Calcium channel blockers & $6(27)$ \\
\hline -Endothelin antagonists & $12(54)$ \\
\hline -Phosphodiesterase inhibitors & $3(14)$ \\
\hline -Parenteral prostacyclin analogues & $8(36)$ \\
\hline -Inhaled iloprost & $3(14)$ \\
\hline -Diuretic & $18(82)$ \\
\hline \multicolumn{2}{|l|}{ Blood tests, median (IQR) } \\
\hline Uric acid (mg/dL) & $5.9(4.8-7.0)$ \\
\hline NT-proBNP (pg/mL) & $1029.5(220.0-1702.3)$ \\
\hline MR-proADM (nmol/L) & $0.7(0.5-1.0)$ \\
\hline Troponin I (pmol/L) & 0 \\
\hline Aldosterone (nmol/L) & $93.7(44.3-163.0)$ \\
\hline Renin (ng/mL) & $11.0(2.9-22.6)$ \\
\hline Sodium (mmol/L) & $140.0(138.0-141.5)$ \\
\hline \multicolumn{2}{|l|}{ Echocardiography, median (IQR) } \\
\hline Estimated PASP $(\mathrm{mmHg})$ & $73.0(59.0-87.5)$ \\
\hline RV end-diastolic diameter (mm) & $39.5(31.0-48.3)$ \\
\hline RV wall thickness (mm) & $5.2(5.0-6.1)$ \\
\hline Right atrial diameter (mm) & $54.0(48.5-69.5)$ \\
\hline IVC inspiratory collapse (\%) & $51.5(29.3-85.8)$ \\
\hline RV fractional area change (\%) & $32.6(22.2-42.3)$ \\
\hline TAPSE (mm) & $18.5(15.0-23.3)$ \\
\hline Tricuspid TDI Sm velocity (cm/s) & $11.5(8.8-13.3)$ \\
\hline RV global longitudinal systolic strain (\%) & $-15.1(-21.3$ to -12.3$)$ \\
\hline $\begin{array}{l}\text { RV global longitudinal systolic strain rate (/s, } \\
\text { GLSRs) }\end{array}$ & $-1.0(-1.2$ to -0.7$)$ \\
\hline LV end-diastolic diameter (mm) & $45.5(41.8-50.5)$ \\
\hline LV EF (\%) & $58.5(58.5-68.8)$ \\
\hline $\begin{array}{l}\text { RV global longitudinal peak early diastolic strain } \\
\text { rate (GLSRe) }\end{array}$ & $0.9(0.6-1.2)$ \\
\hline $\begin{array}{l}\text { RV global longitudinal peak end-diastolic strain } \\
\text { rate (GLSRa) }\end{array}$ & $0.8(0.5-1.0)$ \\
\hline
\end{tabular}

6MWT: 6-Minute Walk Test; ESR: Erythrocyte Sedimentation Rate; IVC: Inferior Vena Cava; LV: Left Ventricular; PAP: Pulmonary Artery Pressure; PASP: Pulmonary Artery Systolic Pressure; RV: Right Ventricular; TAPSE: Tricuspid Annular Peak Systolic Excursion; TDI: Tissue Doppler Imaging; WHO: World Health Organization. Table 1: Baseline clinical, laboratorial and echocardiographic characteristics.

(IQR, 43.0 to 67.5 ) years-old. The majority of patients were female $(68 \%, n=15)$. Etiologic investigation disclosed inoperable chronic thromboembolic disease as the cause of $\mathrm{PH}$ in 5 patients $(23 \%)$. The remaining 17 patients had etiologies that met Group I (Nice criteria 2013). All patients were symptomatic, with $73 \%$ having WHO class II symptoms. 
A negative correlation was seen between the 6 MWT distance and WHO functional class $(S=-0.48, p=0.021)$ and the pretest Borg scale $(\mathrm{S}=-0.52, \mathrm{p}=0.017)$, as shown in Figures 1 and 2, respectively. The 6 MWT distance also correlated with some laboratorial parameters: directly with sodium level $(\mathrm{R}=0.55, \mathrm{p}=0.006)$ and inversely with serum aldosterone $(\mathrm{R}=-0.46, \mathrm{p}=0.030)$, renin $(\mathrm{R}=-0.43, \mathrm{p}=0.046)$ and $\mathrm{MR}-$ proADM ( $\mathrm{R}=-0.53, \mathrm{p}=0.009)$ (Figures 3, 4, 5 and 6, respectively).

There was no statistically significant relationship between the 6 MWT distance and serum levels of NT-proBNP and uric acid.

The only echocardiographic variables that correlated with the 6 MWT distance were GLSRs $(\mathrm{R}=0.49, \mathrm{p}=0.038)$ and GLSRe $(\mathrm{R}=-0.55$, $\mathrm{p}=0.018$ ) (Figures 7 and 8 , respectively). The conventional parameters of the RV function did not show any statistically significant association.

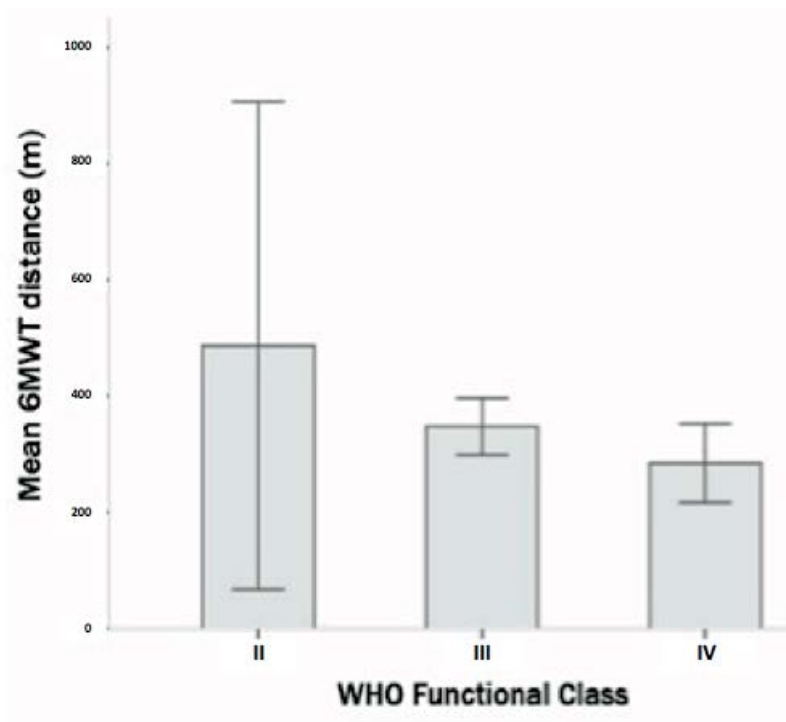

Figure 1: Correlation between 6 MWT distance and WHO functional class in $22 \mathrm{PH}$ patients (at inclusion).

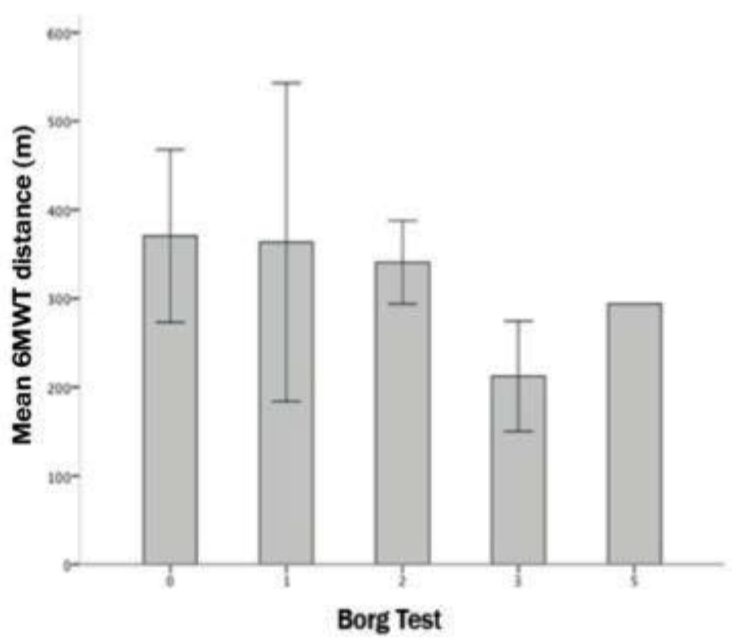

Figure 2: Correlation between 6 MWT distance and pretest Borg scale in $22 \mathrm{PH}$ patients (at inclusion).

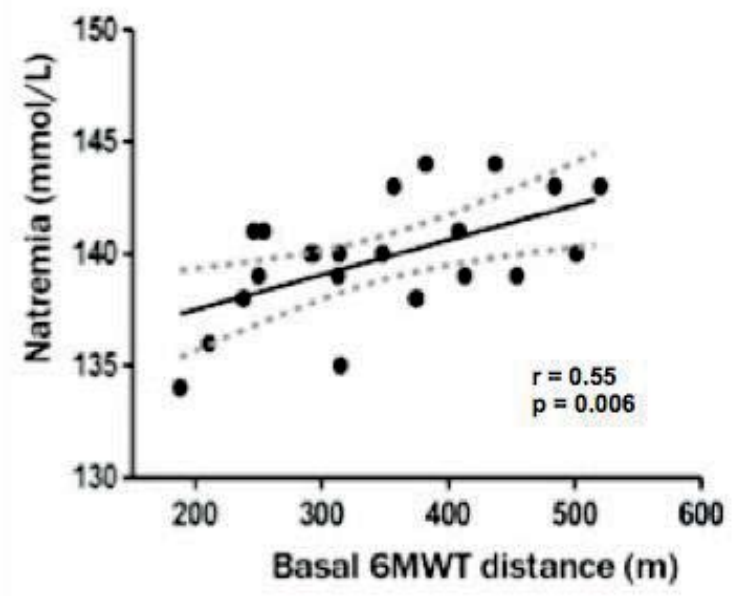

Figure 3: Correlation between $6 \mathrm{MWT}$ distance and natremia in $22 \mathrm{PH}$ patients (at inclusion). The linear regression line is superimposed, surrounded with the $95 \%$ confidence interval lines for the regression line. $r=$ Pearson correlation coefficient. $p=p$ value.

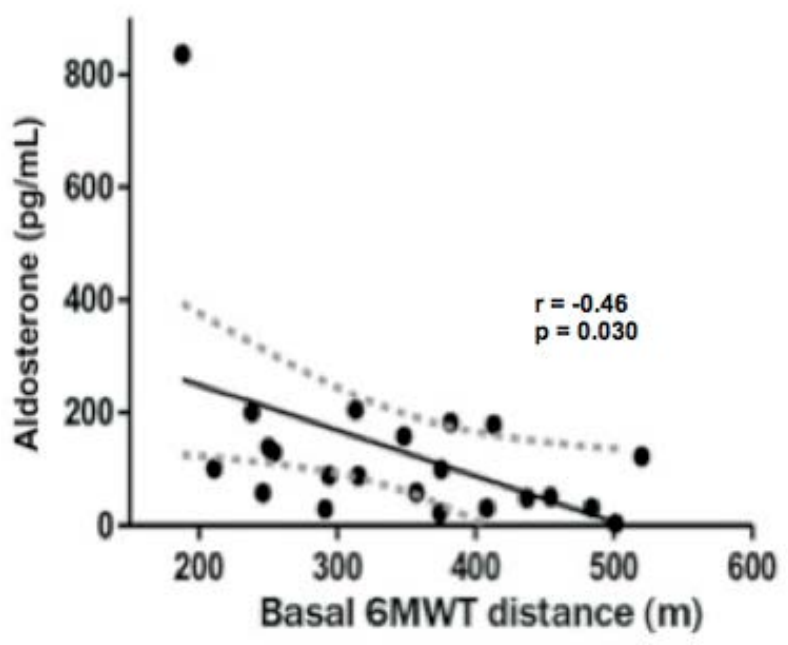

Figure 4: Correlation between 6 MWT distance and serum aldosterone in $22 \mathrm{PH}$ patients (at inclusion). The linear regression line is superimposed, surrounded with the $95 \%$ confidence interval lines for the regression line. $r=$ Pearson correlation coefficient. $p=p$ value.

\section{Discussion}

In the present study, we sought to determine the power of several clinical, laboratorial and echocardiographic variables in predicting the 6 MWT results in patients with PH. We hypothesized that the 6 MWT distance correlated with neurohumoral and echocardiographic parameters reflecting $\mathrm{PH}$ severity.

This study demonstrated that serum concentration of aldosterone, renin, MR-proADM and sodium, in addition to right ventricle strain imaging parameters, correlated with $6 \mathrm{MWT}$ distance. 


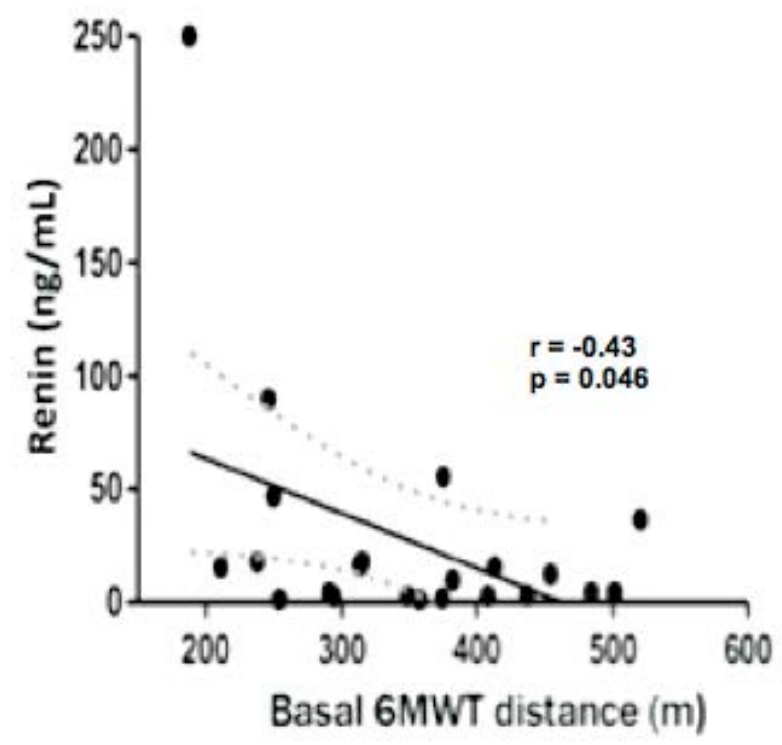

Figure 5: Correlation between $6 \mathrm{MWT}$ distance and renin in $22 \mathrm{PH}$ patients (at inclusion). The linear regression line is superimposed, surrounded with the $95 \%$ confidence interval lines for the regression line. $r=$ Pearson correlation coefficient. $p=p$ value.

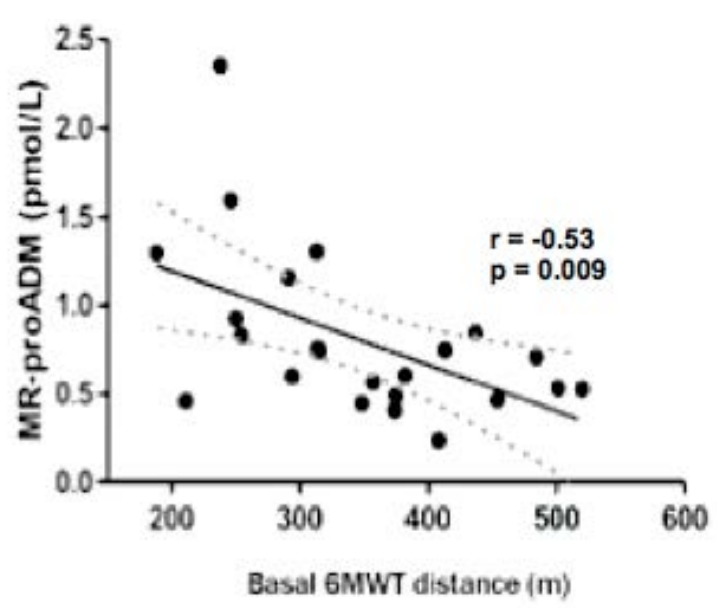

Figure 6: Correlation between 6 MWT distance and MR-proADM in 22 $\mathrm{PH}$ patients (at inclusion). The linear regression line is superimposed, surrounded with the $95 \%$ confidence interval lines for the regression line. $r=$ Pearson correlation coefficient. $p=p$ value.

The successful use of the change in 6 MWT distance as a primary end-point in the pivotal PH trial of IV Epoprostenol [9] paved the way for its use as a primary end-point and indicator of symptom change in other trials for $\mathrm{PH}$ medications. It is the most widely used functional marker because it is derived from a simple test that correlates with hemodynamic variables and the results of cardiopulmonary exercise testing, as and it has prognostic value in the evaluation of $\mathrm{PH}$ patients $[1,10,11]$. By measuring the distance a patient can walk, the 6 MWT can indirectly quantify shortness of breath and fatigue, two of the most common symptoms of $\mathrm{PH}$. However, $\mathrm{PH}$ is a chronic, progressive,

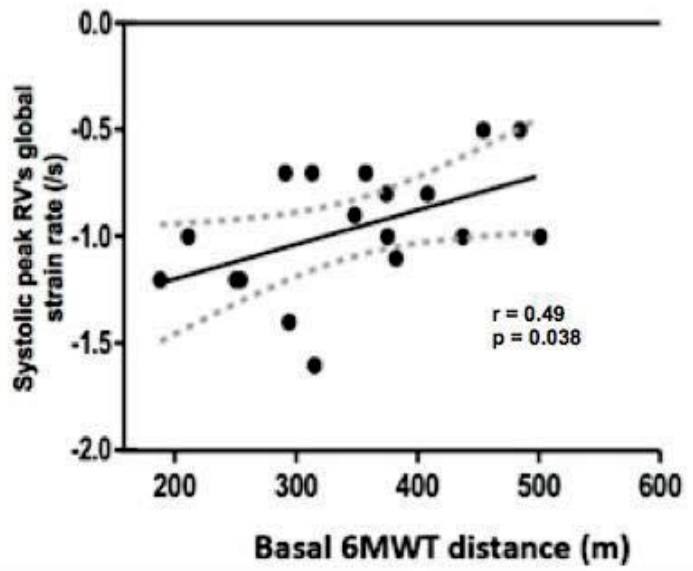

Figure 7: Correlation between 6 MWT distance and GLSRs in $22 \mathrm{PH}$ patients (at inclusion). The linear regression line is superimposed, surrounded with the $95 \%$ confidence interval lines for the regression line. $r=$ Pearson correlation coefficient. $p=p$ value.

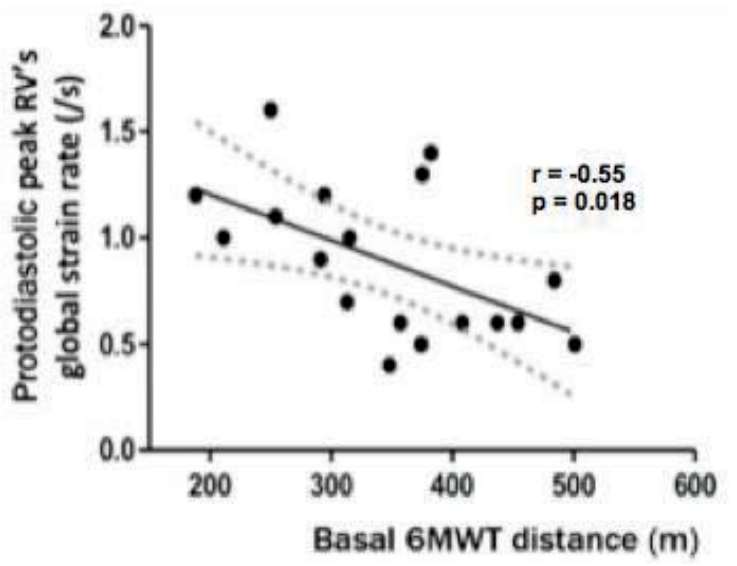

Figure 8: Correlation between $6 \mathrm{MWT}$ distance and GLSRe in $22 \mathrm{PH}$ patients (at inclusion). The linear regression line is superimposed, surrounded with the $95 \%$ confidence interval lines for the regression line. $r=$ Pearson correlation coefficient. $p=p$ value.

functionally debilitating disease, and the relevance of 6 MWT distance to long-term outcomes is questionable.

A correlation exists between increasing exercise capacity and the improvement of several peripheral abnormalities, in the absence of improvement in hemodynamic abnormalities in patients with cardiopulmonary disease [12]. It is possible that the changes that occur in the periphery as a consequence of the systemic effects of heart failure often become the exercise limiting factors more than the heart dysfunction that initiated the syndrome. The complexity of the question should raise the importance of a multi-parameter approach in the care of patients with $\mathrm{PH}$, to help ensure that measures of functional capacity, clinical improvement or worsening and treatment effect are determined objectively.

In respect to biomarkers, a large number of neurohumoral peptides have shown superiority over those commonly used in heart failure and have the potential to be useful in monitoring PH. They offer the possibility of reducing the frequency of use of invasive tests and may be 
particularly useful for screening, predicting the prognosis, monitoring and possibly assist in the selection of therapy of $\mathrm{PH}$ patients. However, to date only brain natriuretic peptide and NT-proBNP have been included as prognostic parameters in the guidelines [4]. The natriuretic peptide system is activated in chronic PH [13,14]. NT-proBNP levels have been related to hemodynamic and functional parameters [15,16], response to medical treatment [17] and mortality in patients with $\mathrm{PH}[18,19]$. Neurohormonal activation of the sympathetic and renin-angiotensinaldosterone system has been demonstrated in patients with $\mathrm{PH}$, and occurs in proportion to the degree of RV dysfunction [20]. Systemic renin-angiotensin-aldosterone activity is increased in patients with $\mathrm{PH}$ and associated with disease progression. Due to increased angiotensin converter enzyme activity, pulmonary endothelial cells of patients with $\mathrm{PH}$ produce more angiotensin II, which in turn induces significant proliferation of pulmonary artery smooth muscle cell, RV afterload and pulmonary vascular remodeling [21]. Several studies have showed the importance of natremia in the evaluation of patients with $\mathrm{PH}$. Forfia et al demonstrated that hyponatremia is associated with advanced right heart failure and reduced survival in patients with $\mathrm{PH}$ and predicted death even after adjusting for hemodynamic, echocardiographic and clinical variables of known prognostic importance in $\mathrm{PH}$ [22]. Our results suggested that natremia and neurohormonal activation biomarkers of the renin-angiotensin-aldosterone system correlate with functional capacity in patients with $\mathrm{PH}$, likely reflecting differences in pulmonary and systemic hemodynamics. Of note, our patients were not treated with angiotensin converting enzyme inhibitors or angiotensin receptor blockers antagonists.

Plasma adrenomedullin is a potent hypotensive peptide that increases pulmonary blood flow. One study demonstrated that plasma adrenomedullin levels were increased in patients with pulmonary arterial hypertension compared with control subjects. Right atrial pressure, mean pulmonary arterial pressure, and pulmonary vascular resistance were highly correlated with adrenomedullin levels [23]. Our study is the first to show a correlation between MR-proADM levels and the $6 \mathrm{MWT}$ results in PH. Patients with a worse performance on 6 MWT had higher levels of MR-proADM, which may be reflecting a compensatory mechanism regarding the vasodilatatory properties of the peptide.

$\mathrm{RV}$ function is an important determinant of outcome in $\mathrm{PH}$, however, its evaluation is challenging because of its geometry. Speckletracking strain echocardiographic evaluation is an easily obtained, angle-independent technique for quantifying myocardial deformation [24-27], including assessment of RV function in $\mathrm{PH}[28,29]$. Sachdev et al. [30] showed that RV longitudinal systolic function by strain and strain rate independently predict future right-sided heart failure, clinical deterioration and mortality in patients with pulmonary arterial hypertension (PAH). An RV free wall strain below $-12.5 \%$ in patients with PAH identified a cohort with marked RV dysfunction and predisposition to clinical deterioration.

In this study, we did not find a correlation between functional capacity (expressed by the $6 \mathrm{MWT}$ distance) and RV global longitudinal systolic strain or TAPSE. However, it was found that patients with poor performance in the $6 \mathrm{MWT}$ had higher RV global longitudinal systolic strain rate. Although the distinction between increased afterload or impaired contractility or both as the cause of deformation variability is difficult and may warrant further investigation, we propose that this finding may reflect adaptive changes of RV mechanics induced by $\mathrm{PH}$.

Insight into the role of diastolic function in $\mathrm{PH}$ patients is scarce. In the past years, research has mainly focused on the influence of $\mathrm{PH}$ on
RV systolic function and the prognostic significance of this parameter [30]. There is evidence that RV diastolic function is impaired in $\mathrm{PH}$ patients. First, due to increased RV afterload, myocardial relaxation and filling may be impaired. Second, the RV compensatory hypertrophy in response to increased afterload reduces ventricular compliance and may impair diastolic function [31]. We found that GLSRe showed an inverted correlation with the $6 \mathrm{MWT}$ distance, possibly reflecting some degree of diastolic dysfunction due to pressure overload and secondary remodeling.

We recognize several limitations of our study. The number of subjects included is small, but in low prevalence diseases such as $\mathrm{PH}$ amassing a large population of patients is rare even in a referral center. Patients were on variable therapies at inclusion. In this regard, recent meta-analysis of $\mathrm{PH}$ trials have consistently shown that while baseline 6 MWT distance strongly predicts survival, changes in 6 MWT distance in response to specific therapies did not predict disease outcomes [11,32]. Furthermore, there are intrinsic limitations of speckle-tracking strain echocardiography including relatively low reproducibility with suboptimal intra- and interobserver variabilities, broad ranges of normal values due to patient-to-patient variability, dependence on image quality and frame rate and image resolution.

\section{Conclusion}

In conclusion, the $6 \mathrm{MWT}$ distance correlated with the activation of the renin-angiotensin-aldosterone system and parameters of RV myocardial deformation. The MR-proADM levels proved to be useful in the prediction of the functional capacity.

\section{References}

1. Hoeper MM, Bogaard HJ, Condliffe R, Frantz R, Khanna D, et al. (2013) Definitions and diagnosis of pulmonary hypertension. J Am Coll Cardiol 62(Suppl): D42-D50.

2. Thenappan T, Shah SJ, Rich S, Gomberg-Maitland M (2007) A USA-based registry for pulmonary arterial hypertension: 1982-2006. Eur Respir J 30: 11031110.

3. Benza RL, Miller DP, Gomberg-Maitland M, Frantz RP, Foreman AJ, et al. (2010) Predicting survival in pulmonary arterial hypertension: insights from the Registry to Evaluate Early and Long-Term Pulmonary Arterial Hypertension Disease Management (REVEAL). Circulation 122: 164-172.

4. Galiè N, Humbert M, Vachiery JL, Gibbs S, Lang I, et al. (2015) ESC/ERS Guidelines for the diagnosis and treatment of pulmonary hypertension: The Join Task Force for the Diagnosis and Treatment of Pulmonary Hypertension of the European Society of Cardiology (ESC) and the European Respiratory Society (ERS) Endorsed by: Association for European Paediatric and Congenital Cardiology (AEPC), International Society for Heart and Lung Transplantation (ISHLT). Eur Heart J.

5. Farber HW, Miller DP, McGoon MD, Frost AE, Benton WW, et al. (2015) Predicting outcomes in pulmonary arterial hypertension based on the 6-minute walk distance. J Heart Lung Transplant 34: 362-368.

6. McLaughlin VV, Badesch DB, Delcroix M, Fleming TR, Gaine SP, et al. (2009) End points and clinical trial design in pulmonary arterial hypertension. J Am Coll Cardiol 54: S97-107

7. Chetta A, Zanini A, Pisi G, Aiello M, Tzani P, et al. (2006) Reference values for the 6-min walk test in healthy subjects $20-50$ years old. Respir Med 100: 1573-1578.

8. Rudski LG, Lai WW, Afilalo J, Hua L, Handschumacher MD, et al. (2010) Guidelines for the echocardiographic assessment of the right heart in adults: a report from the American Society of Echocardiography endorsed by the European Association of Echocardiography, a registered branch of the European Society of Cardiology, and the Canadian Society of Echocardiography. J Am Soc Echocardiogr 23: 685-713.

9. Barst RJ, Rubin LJ, Long WA, McGoon MD, Rich S, et al. (1996) A comparison of continuous intravenous epoprostenol (prostacyclin) with conventional therapy for primary pulmonary hypertension. N Engl J Med 334: 296-301. 
Citation: Plácido R, Martins S, Marques JS, Kovell L, Gonçalves S, et al., (2015) Predictors of Functional Capacity in Patients with Pulmonary Hypertension. J Pulm Respir Med 5: 290. doi:10.4172/2161-105X.1000290

10. Miyamoto S, Nagaya N, Satoh T, Kyotani S, Sakamaki F, et al. (2000) Clinical correlates and prognostic significance of six-minute walk test in patients with primary pulmonary hypertension. Comparison with cardiopulmonary exercise testing. Am J Respir Crit Care Med 161: 487-492.

11. Savarese G, Paolillo S, Costanzo P, D'Amore C, Cecere M, et al. (2012) Do changes of 6-minute walk distance predict clinical events in patients with pulmonary arterial hypertension? A meta-analysis of 22 randomized trials. J Am Coll Cardiol 60: 1192-1201

12. Clark AL, Poole-Wilson PA, Coats AJ (1996) Exercise limitation in chronic heart failure: central role of the periphery. J Am Coll Cardiol 28: 1092-1102.

13. Maeda K, Tsutamoto T, Wada A, Hisanaga T, Kinoshita M (1998) Plasma brain natriuretic peptide as a biochemical marker of high left ventricular end-diastolic pressure in patients with symptomatic left ventricular dysfunction. Am Heart J 135: 825-832.

14. Troughton RW, Frampton CM, Yandle TG, Espiner EA, Nicholls MG, et al. (2000) Treatment of heart failure guided by plasma aminoterminal brain natriuretic peptide (N-BNP) concentrations. Lancet 355: 1126-1130.

15. Leuchte HH, Holzapfel M, Baumgartner RA, Ding I, Neurohr C, et al. (2004) Clinical significance of brain natriuretic peptide in primary pulmonary hypertension. J Am Coll Cardiol 43: 764-770.

16. Nagaya N, Nishikimi T, Okano Y, Uematsu M, Satoh T, et al. (1998) Plasma brain natriuretic peptide levels increase in proportion to the extent of right ventricular dysfunction in pulmonary hypertension. J Am Coll Cardiol 31: 202 208

17. Leuchte $\mathrm{HH}$, Holzapfel M, Baumgartner RA, Neurohr C, Vogeser M, et al (2005) Characterization of brain natriuretic peptide in long-term follow-up of pulmonary arterial hypertension. Chest 128: 2368-2374.

18. Fijalkowska A, Kurzyna M, Torbicki A, Szewczyk G, Florczyk M, et al. (2006) Serum $\mathrm{N}$-terminal brain natriuretic peptide as a prognostic parameter in patients with pulmonary hypertension. Chest 129: 1313-1321.

19. Leuchte $\mathrm{HH}$, El Nounou M, Tuerpe JC, Hartmann B, Baumgartner RA, et al. (2007) N-terminal pro-brain natriuretic peptide and renal insufficiency as predictors of mortality in pulmonary hypertension. Chest 131: 402-409.

20. Velez-Roa S, Ciarka A, Najem B, Vachiery JL, Naeije R, et al. (2004) Increased sympathetic nerve activity in pulmonary artery hypertension. Circulation 110 1308-1312.

21. Nootens M, Kaufmann E, Rector T, Toher C, Judd D, et al. (1995) Neurohormonal activation in patients with right ventricular failure from pulmonary hypertension: relation to hemodynamic variables and endothelin levels. J Am Coll Cardiol 26 : 1581-1585.

22. Forfia PR, Mathai SC, Fisher MR, Housten-Harris T, Hemnes AR, et al. (2008) Hyponatremia predicts right heart failure and poor survival in pulmonary arterial hypertension. Am J Respir Crit Care Med 177: 1364-1369.

23. Kakishita M, Nishikimi T, Okano Y, Satoh T, Kyotani S, et al. (1999) Increased plasma levels of adrenomedullin in patients with pulmonary hypertension. Clin Sci (Lond) 96: 33-39.

24. Ingul CB, Torp H, Aase SA, Berg S, Stoylen A, et al. (2005) Automated analysis of strain rate and strain: feasibility and clinical implications. J Am Soc Echocardiogr 18: 411-418.

25. Leitman M, Lysyansky P, Sidenko S (2004) Two-dimensional strain-a nove software for real-time quantitative echocardiographic assessment of myocardial function. J Am Soc Echocardiogr 17: 1021-1029.

26. Perk G, Tunick PA, Kronzon I (2007) Non-Doppler two-dimensional strain imaging by echocardiography--from technical considerations to clinical applications. J Am Soc Echocardiogr 20: 234-243.

27. Reisner SA, Lysyansky P, Agmon Y, Mutlak D, Lessick J, et al. (2004) Global longitudinal strain: a novel index of left ventricular systolic function. J Am Soc Echocardiogr 17: 630-633.

28. Dambrauskaite V, Delcroix M, Claus P, Herbots L, D'hooge J, et al. (2007) Regional right ventricular dysfunction in chronic pulmonary hypertension. J Am Soc Echocardiogr 20: 1172-1180

29. Meng H, Villarraga HR, Lee P, Aijaz SA, Kittipovanonth M (2007) Pulmonary hypertension is associated with regional right ventricular systolic dysfunction and dyssynchrony: strain and strain rate assessment using velocity vector imaging technique. Circulation 116(suppl 16): 331

30. Sachdev A, Villarraga HR, Frantz RP, McGoon MD, Hsiao JF, et al. (2011) Right ventricular strain for prediction of survival in patients with pulmonary arterial hypertension. Chest 139: 1299-1309.

31. Gan CT, Holverda S, Marcus JT, Paulus WJ, Marques KM, et al. (2007) Righ ventricular diastolic dysfunction and the acute effects of sildenafil in pulmonary hypertension patients. Chest 132: 11-17.

32. Gabler NB, French B, Strom BL, Palevsky HI, Taichman DB, et al. (2012) Validation of 6-minute walk distance as a surrogate end point in pulamonary arterial hypertension trials. Circulation 126: 349-356 